\title{
Analisis Metode Naive Bayes dalam Memprediksi Tingkat Pemahaman Mahasiswa Terhadap Mata Kuliah Berdasarkan Posisi Duduk
}

\author{
Devi Silvia Siltonga1, Saifullah ${ }^{2}$, Rafika Dewi ${ }^{3}$ \\ Mahasiswa Program Studi Sistem Informasi ,STIKOM TUNAS BANGSA PEMATANGSIANTAR \\ Jl.Jenderal Sudirman Blok A No.1/2/3 Pematangsiantar,Medan,Indonesia,21127 \\ Email :devisilvia@gmal.com ${ }^{1}$, saifullah@amiktunasbangsa.ac.id ${ }^{2}$, \\ rapikadewi@amiktunasbangsa.ac.id ${ }^{3}$
}

\begin{abstract}
In the lecture room there can be more than 30 students and not all of them get comfortable sitting positions, comfortable to look forward to, comfortable to see lecturers and comfortable to show what the lecturers say so students who sit in the front position and position behind are not the same understand the subject given by the lecturer. hence the purpose of the study is to describe the influence of seating in the lecture hall on the level of student achievement during lecture hours taking place using the Naive Bayes method, in order to find out whether students sitting in the front position will be more understanding than the sitting position at the back so that they can improve achievement scores . after gaining experience in occupying different seating positions, students are asked to fill out a questionnaire relating to the chosen seating position in each form. It is hoped that this study can determine the effect of understanding students or not on subjects based on seating position so that later the output of this system can be an evaluation material to improve student achievement.
\end{abstract}

Keywords: Students, sitting position, Datamining, Naive Bayes

\begin{abstract}
Abstrak - Didalam ruangan perkuliahan bisa terdapat lebih dari 30 mahasiswa/i dan tidak semuanya mendapatkan posisi duduk yang nyaman, nyaman untuk melihat kedepan, nyaman untuk melihat dosen serta nyaman untuk memperlihatkan apa yang disampaikan dosen sehingga mahasiswa yang duduk pada posisi depan dan posisi dibelakang tidak sama dalam memahami matakuliah yang diberikan dosen. maka tujuan penelitian mendeskripsikan pengaruh tempat duduk di dalam ruang kuliah terhadap tingkat prestasi mahasiswa selama jam perkuliahan berlangsung dengan menggunakan metode Naive bayes ini, agar dapat mengetahui apakah mahasiswa yang duduk di posisi depan akan lebih paham dibandingkan dengan posisi duduk di belakang sehingga dapat meningkatkan nilai prestasi. Setelah mendapatkan pengalaman menduduki posisi tempat duduk yang berbeda, mahasiswa diminta untuk mengisi kuesioner berkaitan dengan posisi tempat duduk yang dipilih disetiap bentuk. Diharapkan penelitian ini dapat mengetahui pengaruh paham atau tidaknya mahasiswa terhadap matakuliah berdasarkan posisi tempat duduk sehingga nantinya hasil ouput dari sistem ini dapat menjadi bahan evaluasi untuk meningkatkan prestasi mahasiswa.
\end{abstract}

Kata kunci : Mahasiswa, Posisi Duduk, DataMining, Naive Bayes

\section{PENDAHULUAN}

Melalui pendidikan di Perguruan Tinggi, mahasiswa di bimbing untuk menjadi seorang yang ahli, profesional dalam suatu ilmu atau bidang keilmuwan, dalam situasi mengikuti kuliah di Perguruan Tinggi tercakup aktivitas 
mendengarkan dosen, berpikir, mencerna dan dapat memecahkan sebuah masalah, berpendapat, bertanya dan berbagai aktivitas fisik dan mental lainnya [1]. Posisi duduk bagi mahasiswa sering kali menjadi masalah dalam mengikuti suatu matakuliah, dimana banyak beranggapan bahwa posisi duduk pada bagian depan akan lebih memahami matakuliah dibandingkan pada posisi duduk dibelakang[2]. Maka dari atas dasar realita tersebut, penulis ingin memprediksi apakah masalah letak tempat duduk berpengaruh terhadap prestasi belajar mahasiswa dalam meningkatkan nilai prestasi dimana metode Naive Bayes dapat mengklasifikasikan setiap permasalahan pada kasus yang akan di terapkan. Keuntungan Penggunaan Naive Bayes adalah bahwa metode ini hanya membutuhkan jumlah data pelatihan yang diperlukan dalam proses pengklasifikasian[3].

Evaluasi yang dilakukan pihak Perguruan Tinggi yang dilakukan dengan memberikan kuisoiner kepada mahasiswa STIKOM Tunas Bangsa Pematangsiantar untuk menentukan paham tidaknya mahasiswa terhadap matakuliah berdasarkan posisi duduk dengan menggunakan beberapa faktor yaitu faktor yang pertama dosen. Faktor kedua sarana dan prasarana. Faktor ketiga posisi duduk.

\section{METODOLOGI PENELITIAN}

\subsection{Metode Pengumpulan Data}

Pengumpulan data yang digunakan untuk penelitian ini terdiri dari :

a. Observasi

Penulis melakukan pengamatan langsung terhadap mahasiswa di STIKOM Tunas Bangsa Pematangsiantar baik mahasiswa yang duduk di depan maupun yang duduk dibelakang dapat menguasai atau memahami matakuliah yang diajarkan.

b. Kuesioner

Yaitu proses pengumpulan data atau informasi dengan cara memberikan sebuah pertanyaan atau pernyatan kepada orang lain. Penulis memberikan kuesioner kepada mahasiswa STIKOM Tunas Bangsa Pematangsiantar mengenai pertanyaan yang berhubungan dengan tingkat pemahaman mahasiswa terhadap matakuliah berdasarkan posisi duduk dengan menggunakan linker 4 yaitu SS, S, C, TS. 
Kuesioner yang digunakan dalam penelitian ini adalah :

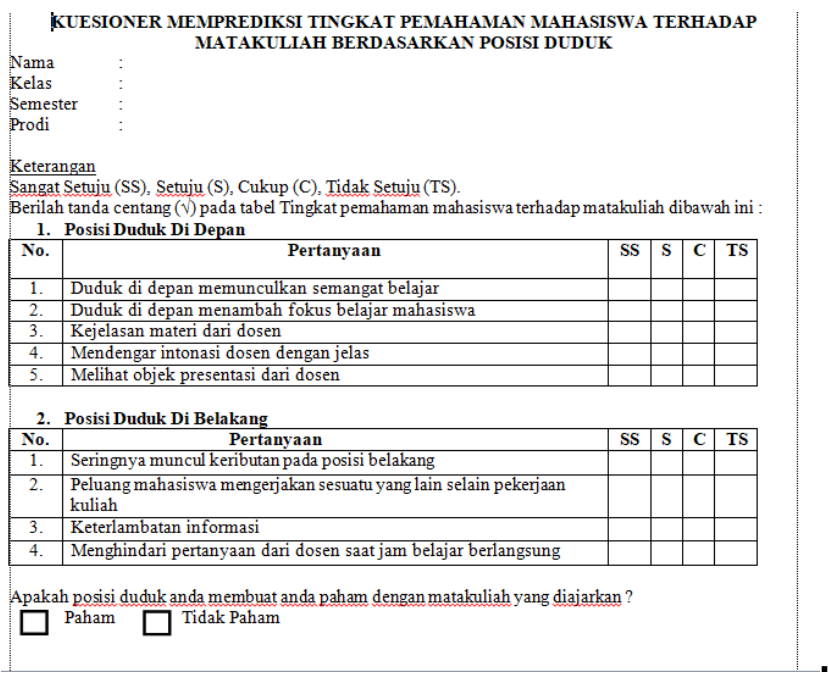

Gambar 1. Data Kuesioner

c. Studi Pustaka

Tahapan ini penulis mengumpulkan data, mempelajari data, dan mencari referensi terkait dengan kasus pada penelitian dengan cara browsing ke internet. Hasil luaran dari studi literatur ini adalah tersusun dan terkoleksinya referensi yang baik dan benar dengan penelitian.

Tabel 1. Data penelitian

\begin{tabular}{|c|c|c|c|c|}
\hline No. & Responden & $\begin{array}{c}\text { Posisi duduk di } \\
\text { Depan }\end{array}$ & Posisi duduk di belakang & Hasil \\
\hline 1. & $\mathrm{R} 1$ & SS & $S$ & Paham \\
\hline 2. & $\mathrm{R} 2$ & $S$ & $\mathrm{C}$ & Paham \\
\hline 3. & R3 & SS & $S$ & Paham \\
\hline 4. & $\mathrm{R} 4$ & SS & $\mathrm{S}$ & Paham \\
\hline 5. & R5 & $S$ & $S$ & Paham \\
\hline 6. & R6 & SS & $S$ & Paham \\
\hline 7. & R7 & SS & $S$ & Paham \\
\hline 8. & R8 & $\mathrm{S}$ & $\mathrm{S}$ & Paham \\
\hline 9. & R9 & SS & SS & Paham \\
\hline 10. & $\mathrm{R} 10$ & $\mathrm{C}$ & $S$ & Paham \\
\hline 11. & R11 & $\mathrm{S}$ & $S$ & $? ? ?$ \\
\hline 12. & $\mathrm{R} 13$ & $S$ & $\mathrm{C}$ & Paham \\
\hline 13. & R14 & $\mathrm{S}$ & $\mathrm{C}$ & Paham \\
\hline 14. & $\mathrm{R} 15$ & $\mathrm{~S}$ & $\mathrm{C}$ & Paham \\
\hline 15. & R16 & $S$ & $S$ & Paham \\
\hline 16. & $\mathrm{R} 17$ & $\mathrm{~S}$ & $\mathrm{~S}$ & Paham \\
\hline 17. & R18 & $S$ & $S$ & Paham \\
\hline 18. & R19 & SS & SS & Paham \\
\hline 19. & $\mathrm{R} 20$ & SS & $\mathrm{S}$ & Paham \\
\hline 20. & $\mathrm{R} 21$ & SS & $S$ & Paham \\
\hline 21. & $\mathrm{R} 21$ & $\mathrm{~S}$ & SS & Paham \\
\hline 22. & $\mathrm{R} 22$ & $\mathrm{~S}$ & $\mathrm{C}$ & Tidak Paham \\
\hline 23. & $\mathrm{R} 23$ & SS & SS & Paham \\
\hline
\end{tabular}

Prediksi Tingkat Pemahaman Mahasiswa Terhadap Mata Kuliah (Devi Silvia Siltonga)|429 


\begin{tabular}{|c|c|c|c|c|}
\hline No. & Responden & $\begin{array}{c}\text { Posisi duduk di } \\
\text { Depan }\end{array}$ & Posisi duduk di belakang & Hasil \\
\hline 24. & R24 & $\mathrm{S}$ & $\mathrm{S}$ & Tidak Paham \\
\hline 25. & R25 & S & S & Paham \\
\hline 26. & R26 & $\mathrm{S}$ & $\mathrm{S}$ & Paham \\
\hline 27. & R27 & S & $\mathrm{C}$ & Tidak Paham \\
\hline 28. & R28 & $\mathrm{S}$ & $\mathrm{S}$ & Paham \\
\hline 29. & R29 & SS & $\mathrm{S}$ & Paham \\
\hline 30. & R30 & $\mathrm{S}$ & SS & Paham \\
\hline 31. & R31 & SS & SS & Paham \\
\hline 32. & R32 & S & $\mathrm{S}$ & Paham \\
\hline 33. & R33 & $\mathrm{C}$ & $\mathrm{S}$ & Paham \\
\hline 34. & R34 & SS & SS & Paham \\
\hline 35. & R35 & SS & SS & ??? \\
\hline 36. & R36 & $\mathrm{S}$ & $\mathrm{S}$ & Paham \\
\hline 37. & R37 & $\mathrm{S}$ & $\mathrm{C}$ & Paham \\
\hline 38. & R38 & SS & $\mathrm{C}$ & Paham \\
\hline 39. & R39 & $\mathrm{S}$ & $\mathrm{S}$ & Paham \\
\hline 40. & R40 & $\mathrm{S}$ & $\mathrm{C}$ & Paham \\
\hline 41. & $\mathrm{R} 41$ & $\mathrm{~S}$ & $\mathrm{~S}$ & Paham \\
\hline 42. & R42 & $\mathrm{S}$ & $\mathrm{S}$ & Paham \\
\hline 43. & R43 & $\mathrm{S}$ & $\mathrm{S}$ & Paham \\
\hline 44. & R44 & $\mathrm{C}$ & SS & Paham \\
\hline 45. & R45 & $\mathrm{C}$ & $\mathrm{S}$ & Tidak Paham \\
\hline 46. & $\mathrm{R} 46$ & $\mathrm{~S}$ & $\mathrm{~S}$ & Paham \\
\hline 47. & R47 & $\mathrm{S}$ & $\mathrm{C}$ & Paham \\
\hline 48. & R48 & $\mathrm{S}$ & $\mathrm{C}$ & Paham \\
\hline 49. & R49 & $\mathrm{S}$ & $\mathrm{S}$ & Paham \\
\hline 50. & R50 & SS & $\mathrm{S}$ & Paham \\
\hline 51. & R51 & $\mathrm{S}$ & $\mathrm{C}$ & Paham \\
\hline 52. & R52 & S & $\mathrm{C}$ & Paham \\
\hline 53. & R53 & SS & $\mathrm{S}$ & Paham \\
\hline 54. & R54 & $\mathrm{S}$ & $\mathrm{C}$ & Paham \\
\hline 55. & R55 & SS & TS & Paham \\
\hline 56. & R56 & $\mathrm{S}$ & $\mathrm{C}$ & Paham \\
\hline 57. & R57 & SS & TS & Paham \\
\hline 58. & R58 & SS & TS & Paham \\
\hline 59. & R59 & $\mathrm{S}$ & TS & Paham \\
\hline 60. & R60 & $\mathrm{C}$ & SS & Paham \\
\hline 61. & R61 & $\mathrm{S}$ & TS & Paham \\
\hline 62. & R62 & $\mathrm{C}$ & SS & Paham \\
\hline 63. & R63 & $\mathrm{S}$ & TS & Paham \\
\hline 64. & R64 & SS & $\mathrm{S}$ & Paham \\
\hline 65. & R65 & $\mathrm{S}$ & $\mathrm{C}$ & Paham \\
\hline 66. & R66 & $\mathrm{S}$ & $\mathrm{S}$ & Tidak Paham \\
\hline 67. & R67 & $\mathrm{C}$ & $\mathrm{S}$ & Tidak Paham \\
\hline 68. & R68 & SS & $\mathrm{S}$ & Paham \\
\hline 69. & R69 & $\mathrm{S}$ & $\mathrm{C}$ & Tidak Paham \\
\hline 70. & R70 & S & $\mathrm{S}$ & Paham \\
\hline
\end{tabular}




\subsection{Data Mining}

Data Mining adalah proses menganalisa data dari perspektif yang berbeda dan menyimpulkannya menjadi informasi-informasi penting yang dapat dipakai untuk meningkatkan keuntungan, memperkecil biaya pengeluaran, atau bahkan keduanya . Data Mining sering juga disebut Knowledge discovery in database (KDD), adalah kegiatan yang meliputi pengumpulan,pemakaian data historis untuk menemukan, pola atau hubungan dalam set data berukuran besar [4]-[7]. Keluaran dari data mining ini bisa dipakai untuk memperbaiki pengambilan keputusan di masa depan, sehingga istilah pattern recognition jarang digunakan karena termasuk bagian dari data mining[8].

\subsection{Naive Bayes}

Naïve Bayes adalah pendekatan statistik yang fundamental dalam pengenalan pola (pattern recognition), pendekatan ini didasarakan pada kuantifikasi trade-off antara berbagai keputusan klasifikasi dengan menggunakan probabilitas dan ongkos yang di timbulkan dalam keputusan tersebut Selain itu Bayesian clasification juga dapat memprediksi probabilitas keanggotaan suatu class[9].

\section{HASIL DAN PEMBAHASAN}

Hasil dan pembahasan pada bab ini disajikan sesuai penelitian yang dilakukan. Data yang digunakan dalam penelitian ini adalah data mahasiswa yang menjawab pertanyaan berdasarkan kuesioner yang telah diberikan. Perangkat lunak yang digunakan yaitu rapidmminer 5.3 untuk menyajikan klasifikasi tingkat pemahaman mahasiswa terhadap matakuliah. Data set yang ada terdiri dari kriteria yang di tentukan yaitu Posisi duduk di depan dan posisi duduk di belakang. Data yang telah didapatkan ditransformasikan ke format data excel 2010. Kumpulan data yang diperoleh digunakan sebagai data masukan dalam membuat model aturan menggunakan algoritma Naive Bayes menggunakan software rapidminer. Dalam mengetahui Paham dan tidak Paham nya mahasiswa terhadap matakuliah berdasarkan posisi duduk dalam mahasiswa di STIKOM Tunas Bangsa Pematangsiantar, penulis akan menampilkan gambaran model aturan dalam mengklasifikasi paham tidaknya mahasiswa terhadap matakuliah berdasarkan posisi duduk menggunakan algoritma Naive Bayes.

\section{Dataset Penelitian}

Metode Naive Bayes digunakan dalam pemodelan data yang akan ditampilkan. Data didapatkan dengan memberikan kuesioner kepada mahasiswa untuk mengetahui apakah mahasiswa paham terhadap matakuliah berdasarkan posisi duduk. Data yang akan diolah ada data training dan data testing. Data training yang digunakan terdapat 68 data sedangkan data testing terdapat 2 data yang digunakan. Kriteria data yang telah ditentukan dianalisis menggunakan perangkat lunak rapidminer 5.3. data Kuesioner yang akan dianalisis memiliki 70 data. 
Tabel 2. Data Training Dalam RapidMiner

\begin{tabular}{|c|c|c|c|c|}
\hline No & Responden & $\begin{array}{c}\text { Posisi duduk } \\
\text { di depan }\end{array}$ & $\begin{array}{c}\text { Posisi duduk } \\
\text { di belakang }\end{array}$ & Hasil \\
\hline 1 & R1 & SS & $S$ & Paham \\
\hline 2 & R2 & $\mathrm{S}$ & $\mathrm{C}$ & Paham \\
\hline 3 & R3 & SS & $S$ & Paham \\
\hline 4 & $\mathrm{R} 4$ & SS & $S$ & Paham \\
\hline 5 & $\mathrm{R} 5$ & $\mathrm{~S}$ & $\mathrm{~S}$ & Paham \\
\hline 6 & R6 & SS & $\mathrm{S}$ & Paham \\
\hline 7 & R7 & SS & $\mathrm{S}$ & Paham \\
\hline 8 & R8 & $\mathrm{S}$ & $S$ & Paham \\
\hline 9 & R9 & SS & SS & Paham \\
\hline 10 & R10 & $\mathrm{C}$ & $\mathrm{S}$ & Paham \\
\hline 11 & R11 & $S$ & $\mathrm{C}$ & Paham \\
\hline 12 & R12 & $\mathrm{S}$ & $\mathrm{C}$ & Paham \\
\hline 13 & R13 & $\mathrm{S}$ & $\mathrm{C}$ & Paham \\
\hline 14 & R14 & $S$ & $S$ & Paham \\
\hline 15 & R15 & $\mathrm{S}$ & $\mathrm{S}$ & Paham \\
\hline 16 & R16 & $\mathrm{S}$ & $\mathrm{S}$ & Paham \\
\hline 17 & R17 & SS & SS & Paham \\
\hline 18 & R18 & SS & $\mathrm{S}$ & Paham \\
\hline 19 & R19 & SS & $\mathrm{S}$ & Paham \\
\hline 20 & $\mathrm{R} 20$ & $\mathrm{~S}$ & SS & Paham \\
\hline 21 & $\mathrm{R} 21$ & $\mathrm{~S}$ & $\mathrm{C}$ & Tidak Paham \\
\hline 22. & $\mathrm{R} 22$ & SS & SS & Paham \\
\hline 23 & R23 & $\mathrm{S}$ & $\mathrm{S}$ & Tidak Paham \\
\hline 24 & R24 & $\mathrm{S}$ & $\mathrm{S}$ & Paham \\
\hline 25 & R25 & $\mathrm{S}$ & $\mathrm{S}$ & Paham \\
\hline 26 & R26 & $S$ & $\mathrm{C}$ & Tidak Paham \\
\hline 27 & R27 & $\mathrm{S}$ & $\mathrm{S}$ & Paham \\
\hline 28 & R28 & SS & $\mathrm{S}$ & Paham \\
\hline 29 & R29 & $\mathrm{S}$ & SS & Paham \\
\hline 30 & R30 & SS & SS & Paham \\
\hline 31 & R31 & $\mathrm{S}$ & $\mathrm{S}$ & Paham \\
\hline 32 & R32 & $\mathrm{C}$ & $\mathrm{S}$ & Paham \\
\hline 33 & R33 & SS & SS & Paham \\
\hline 34 & R34 & $\mathrm{S}$ & $S$ & Paham \\
\hline 35 & R35 & $\mathrm{S}$ & $\mathrm{C}$ & Paham \\
\hline 36 & R36 & SS & $\mathrm{C}$ & Paham \\
\hline 37 & R37 & $\mathrm{S}$ & $\mathrm{S}$ & Paham \\
\hline 38 & R38 & $\mathrm{S}$ & $\mathrm{C}$ & Tidak Paham \\
\hline 39 & R39 & $\mathrm{S}$ & $\mathrm{S}$ & Paham \\
\hline 40 & $\mathrm{R} 40$ & $\mathrm{~S}$ & $\mathrm{~S}$ & Paham \\
\hline 41 & $\mathrm{R} 41$ & $\mathrm{~S}$ & $\mathrm{~S}$ & Paham \\
\hline 42 & $\mathrm{R} 42$ & $\mathrm{C}$ & SS & Paham \\
\hline 43 & $\mathrm{R} 43$ & $\mathrm{C}$ & $\mathrm{S}$ & Tidak Paham \\
\hline 44 & R44 & $\mathrm{S}$ & S & Paham \\
\hline 45 & R45 & $\mathrm{S}$ & $\mathrm{C}$ & Paham \\
\hline 46 & $\mathrm{R} 46$ & $\mathrm{~S}$ & $\mathrm{C}$ & Paham \\
\hline 47 & R47 & $\mathrm{S}$ & $\mathrm{S}$ & Paham \\
\hline 48 & $\mathrm{R} 48$ & SS & $\mathrm{S}$ & Paham \\
\hline 49 & R49 & $S$ & $\mathrm{C}$ & Paham \\
\hline 50 & $\mathrm{R} 50$ & $S$ & $\mathrm{C}$ & Paham \\
\hline
\end{tabular}




\begin{tabular}{|c|c|c|c|c|}
\hline No & Responden & Posisi duduk & Posisi duduk & Hasil \\
\hline 51 & R51 & SS & S & Paham \\
\hline 52 & R52 & S & C & Paham \\
\hline 53 & R53 & SS & TS & Paham \\
\hline 54 & R54 & S & C & Paham \\
\hline 55 & R55 & SS & TS & Paham \\
\hline 56 & R56 & SS & TS & Paham \\
\hline 57 & R57 & S & TS & Paham \\
\hline 58 & R58 & C & SS & Paham \\
\hline 59 & R59 & S & TS & Paham \\
\hline 60 & R60 & C & SS & Paham \\
\hline 61 & R61 & S & TS & Paham \\
\hline 62 & R62 & SS & S & Paham \\
\hline 63 & R63 & S & C & Paham \\
\hline 64 & R64 & S & S & Tidak Paham \\
\hline 65 & R65 & C & S & Tidak Paham \\
\hline 66 & R66 & SS & S & Paham \\
67 & R67 & S & C & Tidak Paham \\
68 & R68 & S & S & Paham
\end{tabular}

Dimana Kuesioner yang diberikan menggunakan linker 4 yang terdiri dari SS (Sangat setuju), S (Setuju), C (Cukup), TS (Tidak Setuju).

\subsection{Menu}

Berikut akan dijelaskan bagian dari menu awal pada tools rapidminer seperti tampilan awal dari rapidminer dan akan dimulai dengan menu new process.

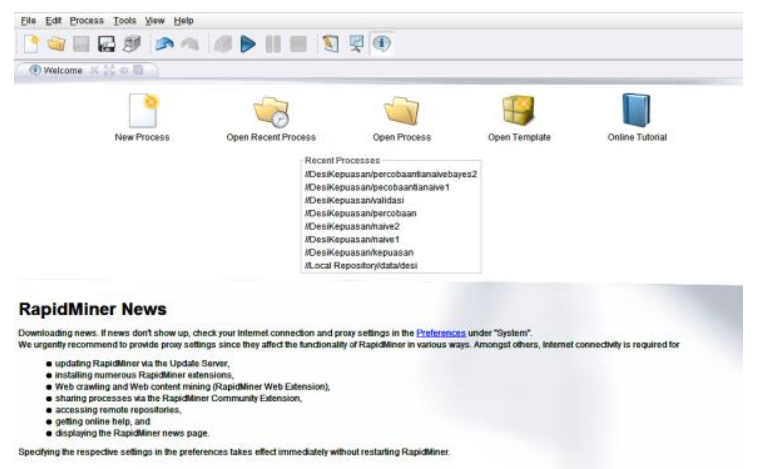

Gambar 2. Tampilan Awal Rapidminer

Pada tampilan berikut terdapat beberapa menu pilihan seperti New Process, Open Recent Process, Open Process, Open Template dan Online Tutorial. Penjelasan dari menu diatas adalah sebagai berikut:

1. New Process Menu ini berisikan tampilan awal jika kita akan membuat proses baru dengan data baru yang belum pernah ada dalam tools ini.

2. Open Recent Process Berfungsi untuk menampilkan dan membuka proses yang baru saja dibuat dengan jangka waktu tertentu, biasanya akan langsung muncul pada tampilan awal tools tanpa harus mencari pada penyimpanan lokal.

3. Open Process Menu ini berfugsi untuk membuka proses yang telah dibuat sebelumnya yang telah kita simpang di penyimpanan lokal. 
4. Open Template Menu ini berisikan pilihan-pilihan proses lain yang telah disediakan oleh tools rapidminer.

5. Online Tutorial Menu ini digunakan untuk memulai tutorial atau tahapan secara online. Tutorial berfungsi untuk memberikan pengenalan dan beberapa konsep data mining.

\subsection{Masukan (Input) Sistem}

Dalam menjalankan proses dalam membentuk model aturan, terlebih dahulu importing data dari data yang sudah di transformasi terlebih dahulu ke dalam microsoft word excel dan diakses menggunakan software Rapidminer. Tahapan dapat dilihat pada gambar dibawah ini.

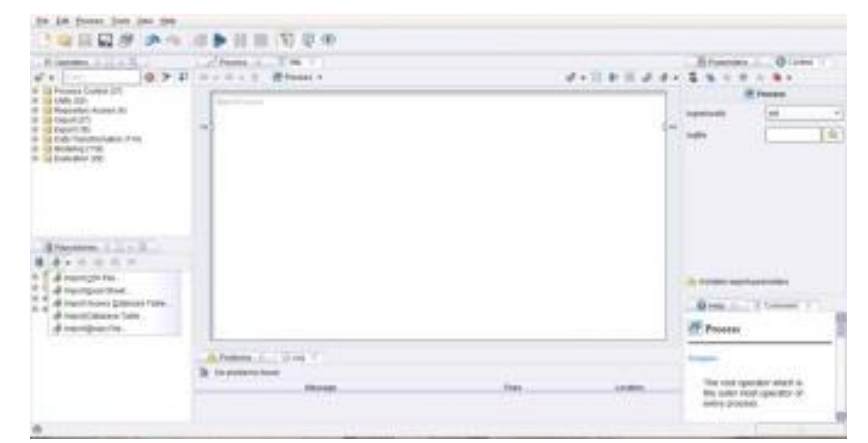

Gambar 3. New Process untuk Import Data Excel

\subsection{Keluaran (Output) Sistem}

Hasil akhir yang akan ditampilkan adalah berupa SimpleDistrubition yaitu menentukan banyaknya nilai dari data kelas paham dan tidak paham. Dapat dilihat pada gambar 4

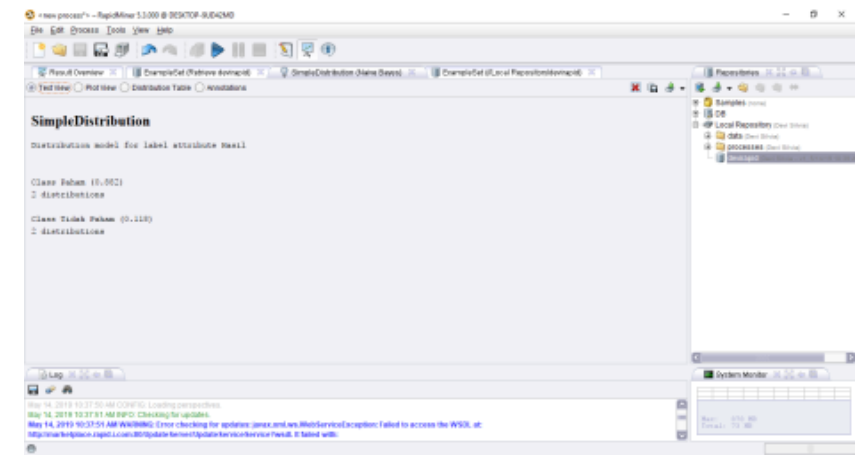

Gambar 4. Hasil Akhir

Berdasarkan gambar 4.10 menjelaskan bahwa kelas Tidak Paham memiliki nilai klasifikasi/probabilitas 0,118 sedangkan kelas Paham mendapatkan nilai klasifikasi/probabilitas 0,882.

Sehingga berdasarkan data hasil klasifikasi pada gambar 4 didapatkan grafik hasil dari rapidminer 5 berikut ini : 


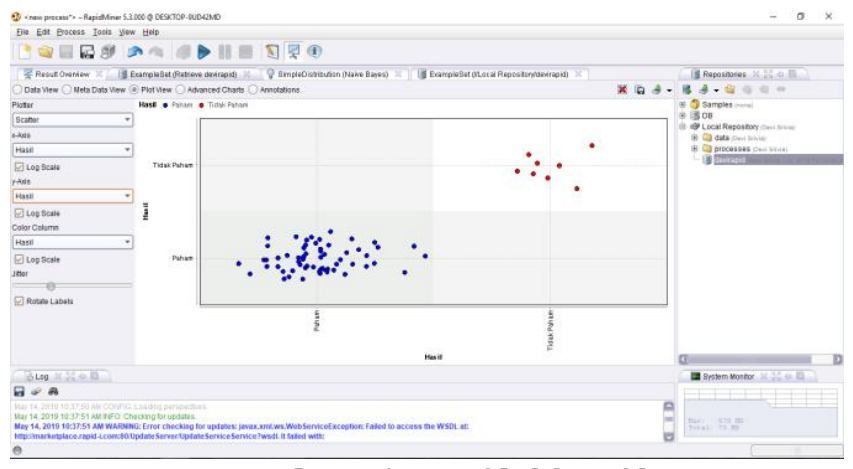

Gambar 5. Grafik klasifikasi

Berdasarkan pada gambar 5 dapat diketahui bahwa pada titik berwarna biru (paham) memiliki banyak node yaitu 60, sedangkan pada titik berwarna biru (Tidak paham) memiliki hanya 8 node.

Akurasi Hasil pengujian Model Algoritma Naive Bayes Classfier ditunjukan pada gambar berikut:

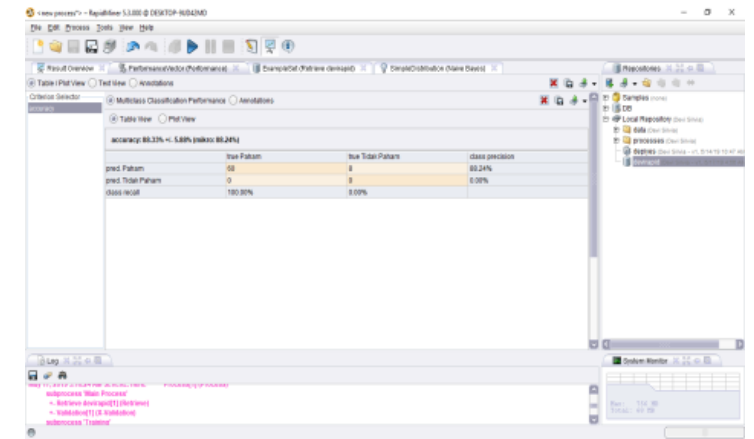

Gambar 6. Nilai Accuracy Performance

\section{KESIMPULAN}

Berdasarkan hasil dari penelitian ini, dapat disimpulkan beberapa hal mengenai Penerapan Metode Naive Bayes dalam Menentukan Tingkat pemahaman mahasiswa terhadap matakuliah berdasarkan posisi duduk dapat digunakan sebagai salah satu metode untuk klasifikasi, dengan parameter posisi duduk didepan dan posisi duduk dibelakang. Bedasarkan 68 data traning yang diolah dalam Rapidminer, Berdasarkan 68 data training yang diolah di dalam Rapidminer, hasil pengujian menunjukkan akurasi sebesar $88.24 \%$ yaitu 8 responden menyatakan ketidakpahaman dan 60 responden menyatakan paham terhadap tingkat pemahaman mahasiswa terhadap matakuliah berdasarkan posisi duduk. Dengan class precision pada prediksi tidak paham memiliki nilai $0 \%$, sedangkan pada prediksi paham memiliki nilai $88.24 \%$. Class recall pada true tidak paham memiliki nilai $0 \%$, sedangkan pada true paham memiliki nilai $100 \%$. Sehingga dapat dikatakan bahwa mahasiswa STIKOM Tunas Bangsa Pematangsiantar paham terhadap pemahaman mahasiswa terhadap matakuliah berdasarkan posisi duduk .

\section{DAFTRA PUSTAKA}

[1] C. Fadlan, S. Ningsih, and A. P. Windarto, "PENERAPAN METODE NAÏVE BAYES DALAM 
KLASIFIKASI KELAYAKAN KELUARGA PENERIMA BERAS RASTRA," JUTIM, vol. 3, no. 1, pp. $1-8,2018$.

[2] S. Haryati, A. Sudarsono, and E. Suryana, "Implementasi Data Mining untuk Memprediksi Masa Studi Mahasiswa Menggunakan Algoritma C4.5," Jurnal Media Infotama, vol. 11, no. 2, pp. 130-138, 2015.

[3] E. Manalu and F. A. S. M. R. Manalu, "PENERAPAN ALGORITMA NAIVE BAYES UNTUK MEMPREDIKSI JUMLAH PRODUKSI BARANG BERDASARKAN DATA PERSEDIAAN DAN JUMLAH PEMESANAN PADA CV . PAPADAN MAMA PASTRIES," Jurnal Mantik Penusa, vol. 1, no. 2, 2017.

[4] I. Parlina, A. P. Windarto, A. Wanto, and M. R. Lubis, "Memanfaatkan Algoritma K-Means dalam Menentukan Pegawai yang Layak Mengikuti Asessment Center untuk Clustering Program SDP," CESS (Journal of Computer Engineering System and Science), vol. 3, no. 1, pp. 87-93, 2018.

[5] M. G. Sadewo, A. P. Windarto, and A. Wanto, "Penerapan Algoritma Clustering dalam Mengelompokkan Banyaknya Desa/Kelurahan Menurut Upaya Antisipasi/ Mitigasi Bencana Alam Menurut Provinsi dengan K-Means," KOMIK (Konferensi Nasional Teknologi Informasi dan Komputer), vol. 2, no. 1, pp. 311-319, 2018.

[6] S. Sudirman, A. P. Windarto, and A. Wanto, "Data Mining Tools | RapidMiner: K-Means Method on Clustering of Rice Crops by Province as Efforts to Stabilize Food Crops In Indonesia," IOP Conference Series: Materials Science and Engineering, vol. 420, no. 12089, pp. 1-8, 2018.

[7] R. W. Sari, A. Wanto, and A. P. Windarto, "Implementasi Rapidminer dengan Metode K-Means (Study Kasus: Imunisasi Campak pada Balita Berdasarkan Provinsi)," KOMIK (Konferensi Nasional Teknologi Informasi dan Komputer), vol. 2, no. 1, pp. 224-230, 2018.

[8] A. N. Putri, "PENERAPAN NAIVE BAYESIAN UNTUK PERANKINGAN KEGIATAN DI FAKULTAS TIK UNIVERSITAS SEMARANG," Jurnal SIMETRIS, vol. 8, no. 2, pp. 603-610, 2017.

[9] L. Krissadi and G. Sekar, "HUBUNGAN LETAK TEMPAT DUDUK DENGAN PENCAPAIAN NILAI AKHIR BLOK MAHASISWA FAKULTAS KEDOKTERAN UMM ANGKATAN 2008 Alpha Cronbach Hasil Reliabel," no. 2003, pp. 18-21, 2012. 